\section{THE NECESSITY FOR MEDICAL TRUSTEESHIP AND FOR A CENTRAL LABORATORY IN STATE MEDICAL INSTITUTIONS.*}

\author{
A. P. OHLMACHER, M.D. \\ Superintendent of the Ohfo Hospital for Epileptics. \\ GALLIPOLIS, OHIO.
}

The contact between the medical profession and the state medical institutions is not close enough. This is true everywhere in the United States. It is particularly true in Ohio. Among the thirty-five trustees governing the eight principal state hospitals in Ohio there are at present but three medical men as members of the boards. To be sure, the medical profession has a representative as local executive head of these hospitals and a number of medical men are employed in the capacity of assistant physicians. But in the real governing body, the one vested with final authority in all important matters, physicians are conspicuous by their absence. Such a condition is bad both for our profession and for the state institutions. The medical profession has much to gain from the proper administration of the state hospitals, and particularly in so far as it concerns the use of the vast material of these hospitals for the advancement of medical knowledge. The state hospitals are much in need of the support that would be afforded by active, broad-minded medical representation on the boards of "nstees, for it is a fact generally conceded that the strictly medical work, and particularly the scientific work in these institutions, is far below what it should be.

As concerns the individual institntions, this state of affairs could be remedied by placing on each managing board at least one progressive medical man who could educate his fellow-trustees to the needs of the institution, and who, with his colleagues on the board, could secure the r spectful attention of the state authorities and of the legislature. It would be needful, of course, to have in each institution an executive head who would be in warm sympathy with the ideas of medical improvement, and who would work in conjunction with the medical trustee.

It seems to me that a great and powerful organization that is working for the most unselfish of purposes- the advancement of human knowledge and the alleviation of human suffering-such as our medical profession is getting to be, should assert its right to participate in the management of the immense state medical institutions which are, after all, but creatures of our profession, and which each and all contain a vast storehouse of knowledge, for the most part now uncultivated. Our profession should declare in unmistakable terms that mere questions of shelter, food, and raiment are not the most important considerations in the conduct of these institutions; they should be, in reality, more than great stateendowed hotels for the insane and epileptic. Our obligations to humanity demand that as scientific medical men we should enter these hospitals and use their material for study, the aim of which should be the solving of the problems that surround the causation, prevention and treatment, not alone of insanity and epilepsy, but of other diseases such as are invariably found among an assemblage of eight thousand ailing human beings like those now filling the Ohio state hospitals. I predict that success would attend the effort were the now wellorganized Ohio State Medical Association to make a formal request for medical representation on the govern-

- Address before the first meeting of the Ninth Councilor District Medical Society, Jackson, Ohio. ing boards of the state medical institutions, and I believe it would be possible for the association to secure favorable attention to the candidates whom it might, because of their peculiar qualifications, suggest for these positions.

By bringing into each individual institution a new impetus for scientific work through the efforts of an active medical trustee, much good could be accomplished. Funds could readily be found for a better equipment for medical, surgical and scientific work, and a high grade of physicians could be attracted to the service of the state. By this means a more intimate touch between the medical profession and the state institutions could be secured.

There is another plan that will bring the medical profession of the state at large in sympathetic relationship with the state hospitals, and that is by the establishment of a central pathologic institute as part of the state hospials' system. The idea is certainly not original, for in the first place at least one state, New York, has already established and placed in successful operation a central pathologic institute; and the project is under way in Michigan, and is being actively discussed in Iowa and elsewhere. But there is a phase of the plan outlined for our state which is unique, and I believe important, and that is the one which proposes that the initiative in the movement looking to the establishment of a central laboratory be taken by the Ohio State Medical Association and that the preponderance of power in the management of its affairs be left in the hands of representatives from the association. To a considerable extent this would make the central laboratory a creature of the state association and the active interest of the medical profession would be retained.

In order further to make the central laboratory of the state medical institutions beneficial to the profession as a whole, it has been suggested that the collection of gross pathologic specimens which naturally would soon be assembled be held open to the profession of the state to become the pathologic exhibit of the state association. Further it would be desirable to have tables in the institute reserved for the use of members of the state association properly qualified to prosecute original research along such lines as would come within the scope of a pathologic institute.

Most of the members of the Ninth Councilor District assembled here to-day are doubtless aware that the project of a state pathologic institute was indorsed by the Ohio State Medical Association at its last annual meeting; that resolutions commending the plan were adopted, and a committee appointed to forward the movement. It was planned to bring the project to the attention of the general assembly which soon convenes. As a member of the Committee on the State Pathologic Institute I am prepared to say that plans have been formulated for an active campaign during the coming session of the legislature. The committee, however, needs the hearty support of every member of the association who can reach a state legislator, and I bespeak the active co-operation of the members of the Ninth Councilor District in our propaganda.

Given a laboratory located in Columbus, sheltered from political interference by the Ohio State University, drawing its material from the several state medical institutions in Columbus and from those scattered throughout the state, properly equipped and judiciously directed, the medical profession of Ohio would have a product to 
which it could point with pride, and the state an addition to its medical institutions whose benefits would ultimately reach all its citizens.

\section{A PLEA FOR UNIFICATION AND UNIFORM ORGANIZATION.}

J. N. MCCORMACK, M.D.

Chairman of the Committee on Organization of the American Med ical Association.

BOWLING GREEN, KY.

To the Medical Profession of the State of New York:

After correspondence on the subject with members of the Joint Conference Committee and others, more especially on the society side, I have been requested, as chairman of the committee which has had this work in charge from its inception, to prepare for publication an explanation of the plan of organization for state and county societies which has been so generally adopted in the last two or three years. As the plan was prepared and is recommended for universal adoption, is already in satisfactory operation in 32 states and in over 1,500 counties, and is likely to be adopted in nearly all of the other states as soon as their annual meetings occur, as the subject is one of interest at this time to every member and well-wisher of our profession, and more especially as the preparation of the plan for general adoption makes my committee as responsible to you for anything wrong in it as though we were members of your county and state societies, it seems entirely proper that the request should be complied with.

An attempt will be made to place beyond question the truth of the following propositions:

1. That existing professional conditions and estrangements are useless and senseless; that they are hurtful almost beyond calculation to both the profession and the public welfare, and that they are remediable.

2. That the plan of organization is based on our system of civil government; that it was prepared with much care and unselfishness, and that it contains nothing untried, experimental or impracticable.

3 . That the county society is not only the unit of the organization, but the source of all authority and power in both the state and national bodies through a representative delegate system, and it is also the only portal of entry to the entire society system.

4. That coincident membership has been an old and perfectly satisfactory method in many states, is essential to complete organization, and that it is just and right. It would be as unfair to permit a physician to become a member of his county society and enjoy all the benefits arising from the labors of the state society, as to permit one to become a citizen of Ithaca or Troy without becoming a citizen of the State of New York and bearing the burdens and responsibilities of the same.

5. That amendment of any part of the plan is purposely made easy and is controlled by delegates from, and responsible alone to, the county societies.

6. That the time has come for unification, and that, while union under a defective plan, which the joint body could modify and improve for the common good, would be far preferable to a continuation of existing conditions, the one now proposed has been found excellent and practical after full trial in other states, and having been prepared away from New York contentions and controversies, it offers a basis for compromise honorable alike to both factions and to neutrals.

In order to establish these propositions clearly and satisfactorily, a brief history of this reorganization movement is necessary. From the very outset the magnitude of our task grew on us. Although in name medical societies-city, district, state and national-existed without number, and medical machinery and highsounding official titles were provided sufficient for the civilized world, mombership in most of them was small and little more than nominal, and, outside of a few states and localities, the profession was so torn with dissensions that it was in chronic disgrace in its own and in public estimation, and in a large measure robbed of its power, by legislation or otherwise, to help either itself or the public, for whose benefit it was supposed to exist. Into a profession already so overcrowded that there was less room and remuneration for the average physician than for clerks and skilled laborers, commerc:al medical colleges were annually turning loose thousands of new graduates, many poorly equipped for intelligent modern practice, and practically all of them without an hour's training in professional conduct, business methods, the importance of society membership, in which all should have been drilled with the care due to subjects to become of so much importance as soon as they come to serve the public and face the problem of earning an honorable livelihood.

Largely as a result of such lack of training, we found that of the 120,000 registered physicians in this country, only about $30,000-0$ ne in four-had ever been members of any kind of soc:ety, local, state or national. Most cities were little better organized than the country districts, a large submerged element being often found within an easy walk of imposing medical and post graduate schools, libraries and hospitals, who had long lost hope of advancement, looked on their profession only as a doubtful means of support, while those in the higher ranks wrangled and slandered each other and brpught odium on all, and Eddyism and other forms of bald quackery took the cream of a patronage which a united, self-respecting and honored profession would have deserved and received.

It was soon found, however, that these conditions, deplorable alike to the profession and public, were not universăl. In Alabama, for instance, under a model plan of organization and resulting united profession, with over 1,500 of the 1,700 physicians members of the county and state societies, medical opinion was sought for the guidance of law-makers, executives and courts, the profession was honored and independent, and quackery was unknown. Kentucky, striving for the same ends under less perfect methods, had had no itinerant or advertising doctor within her borders for ten years, and the profession was aspiring to its rightful place as a directing frrce in public affairs. In a dozen cities also, usually of the lesser rank in population, under similar influences, harmony, co-operation and measurable prosperity prevailed and was increasing.

Inquiry soon demonstrated that the personnel of the profession was much the same everywhere, and the difference in the conditions found were apparently entirely due to difference in methods of organization. After all proper allowance for personal equation in rulers, govcrnments are liberal or despotic as determined by their organic laws, and probably quite as much as with a nation, the constitution and by-laws of a med:cal society will set the compass and shape the policy which will largely determine the future for both itself and its individual members.

Influenced by such belief and cons derations, my committee began ts work four years ago by grouping those 